\title{
A utilização do método de coleta de dados via internet na percepção dos executivos dos institutos de pesquisa de mercado atuantes no Brasil
}

The use of internet data collection method as perceived by executives in market research institutes in Brazil

L'utilisation de la méthode de collecte de données par internet sous la perception des cadres des instituts de recherche de marché actifs au Brésil

El uso del método de recogida de datos por internet en la opinión de los ejecutivos de los institutos de investigación de mercado activos en Brasil

\author{
Vasiliki Evangelou Calliyeris* \\ Alexandre Luzzi Las Casas**
}

Recebido em 13/9/2011 revisado e aprovado em 2/12/2011; aceito em 17/1/2012

\begin{abstract}
Resumo: O presente artigo tem por objetivo apresentar as percepções dos executivos dos institutos brasileiros de pesquisa de mercado sobre a coleta de dados via internet, bem como evidenciar quais são as principais vantagens e desvantagens desse método. Vários pontos fortes e fracos foram identificados no estudo, e os institutos de pesquisa devem se mobilizar para encontrar alternativas criativas para superar as desvantagens apontadas. Palavras-chave: Web survey ${ }^{1}$. $C A T I^{2}$. $C A P I^{3}$.

Abstract: This article objective is to expose the perceptions of the executives of the Brazilian market researcher institutes regarding data collection by internet, as well as to evidence which are the main advantages and disadvantages of this method. Strength and weakness had been identified in the study, and researchers must act to find alternatives to overcome the mentioned fragilities.

Key words: Web survey. CATI. CAPI.

Résumé: Le présent article a pour but de présenter les perceptions des cadres des instituts de recherche de marché brésiliens sur la collecte des données par moyen électronique et de mettre en évidence les principaux avantages et désavantages de cette méthode. Plusieurs points forts et faibles ont été identifiés dans cette étude, et les instituts de recherche doivent se mobiliser afin de trouver des alternatives créatives pour surmonter les désavantages montrés. Mots-clés: Web survey. CATI. CAPI.

Resumen: Este artículo tiene como objetivo presentar las percepciones de los ejecutivos de los institutos de pesquisa de mercado brasileños sobre la recopilación de datos por internet, así como evidenciar cuáles son las principales ventajas y desventajas de este método. Varios puntos fuertes y débiles fueron identificados en el estudio, y los institutos de pesquisa deben movilizarse para encontrar alternativas creativas para superar las desventajas señaladas. Palabras claves: Web survey. CATI, CAPI.
\end{abstract}

\section{Introdução}

Como o número de usuários da Internet dobra a cada ano no mundo, atingindo a marca de cerca de 68 milhões de usuários em 2008 no Brasil (Fonte: IBGE - Pesquisa Nacional por Amostra de Domicílios [PNAD], 2009), investigadores têm utilizado mais frequentemente as ferramentas eletrônicas/ virtuais como método de coleta de dados.
Segundo Dillman (1999), os avanços mais significativos em metodologia de pesquisa durante o século XX foram a introdução da amostra randômica, nos anos 1940, e a entrevista telefônica, nos anos 1970 . No final dos anos 90 e início do século XXI, pesquisadores testemunharam avanço similar com a introdução das pesquisas com suporte tecnológico, como as conduzidas via internet e pelos sistemas de reconhecimento de voz

\footnotetext{
* Administradora pela FGV-SP, pós-graduada em gestão empresarial pela FIA-USP e mestranda em administração pela PUCSP. Diretora Técnica do Instituto de Pesquisa QualiBest - SP. E-mail: vasiliki. calliyeris@me.com

** Professor titular da PUCSP, doutor em administração pela FGV-SP, professor e pesquisador com atuação no Brasil e exterior. Autor de vários livros e líder do grupo de pesquisa MARCO - núcleo de pesquisa em marketing e comunicação, da PUC-SP. E-mail: alascasas@terra.com.br

${ }^{1}$ Levantamento, coleta de dados via web (World Wide Web - que em português significa, "Rede de alcance mundial"; conhecida como web e www - é um sistema de documentos em hipermídia que são interligados e executados na Internet). Fonte: http://pt.wikipedia.org/wiki/World_Wide_Web.

${ }^{2}$ Computer Assisted Telephone Interviewing - entrevistas telefônicas assistidas por computador.

${ }^{3}$ Computer Assisted Personal Interviewing - entrevistas pessoais assistidas por computador.
} 
(voice recognition systems ou interactive voice recognition - IVR).

Couper (2000) assinala que o poder da web reside não apenas no fato de ela atingir um incontável número de respondentes através de um custo baixo, mas também no fato de que ela se tornou acessível, como meio de coleta, para a população em geral, que pode oferecer produtos e serviços em sites e, simultaneamente, coletar dados de consumidores, potenciais clientes e curiosos, que diariamente acessam os ambientes virtuais em busca de informações.

Além disso, essa capacidade de coletar dados em larga escala não se restringe mais a organizações governamentais ou a grandes empresas do mundo corporativo. O baixo custo da pesquisa via web tornou sua aplicabilidade acessível a qualquer pessoa com acesso à Internet e democratizou definitivamente o processo de coleta de dados. Para completar, a utilização de recursos multimídia, facilitou a padronização (do instrumento de coleta) e a interação do respondente com o método de autopreenchimento, tornando-o amigável e dinâmico.

Nesse sentido, desde a sua implementação, como método contemporâneo de coleta de dados, a pesquisa via web vem sendo tema de várias investigações no meio científico, que debate, desde então, sua eficácia e aplicabilidade e propõe soluções para os principais problemas encontrados. Países como os Estados Unidos utilizam a coleta de dados por internet desde o final dos anos 1990 e, por isso, já superaram alguns dos principais problemas de sua utilização. Já o Brasil tenta, desde o início dos anos 2000, migrar dos métodos de coleta tradicionais (presencial e telefônico) para a recolha via web, faceando, nestes últimos 10 anos, os benefícios e as dificuldades de sua aplicabilidade.

O presente artigo tem por objetivo apresentar as percepções dos executivos dos institutos brasileiros de pesquisa de mercado sobre a coleta de dados por meio eletrônico, bem como evidenciar quais são as principais vantagens e desvantagens desse método em um país de dimensões continentais, diferenças socioeducacionais extremas e culturalmente acostumado a pesquisas intermediadas por entrevistadores.

\section{A pesquisa de mercado via web}

É unânime a opinião de vários autores quanto às duas principais vantagens da utilização do método de coleta de dados via web: seu baixo custo (THACH, 1995; COUPER, 2000; BETHLEHEM, 2010; FRICKER et al., 2005; COUPER; MILLER, 2008; FLEMING; BOWDEN, 2009) e a velocidade de sua condução (THACH, 1995; GUNTER et al., 2002; BETHLEHEM, 2010; McDONALD; ADAM, 2003).

O baixo custo inclui desde a economia com entrevistadores, com a impressão de questionários, até com o custo de digitação (sendo os dois últimos itens, quando comparada à técnica com a entrevista pessoal, quando esta tem como instrumento de coleta o papel e a caneta). Já a velocidade na condução da pesquisa refere-se ao fato de os questionários, e suas respectivas respostas, poderem ser entregues em "segundos virtuais". Ademais, a tabulação dos dados pode ser feita eletronicamente e disponibilizada em tempo real.

A vantajosa aplicabilidade do método de coleta de dados via web em determinados segmentos da população foi mencionada por Sproull e Kiesler (1991) e por Kiesler (1997) os quais atestam que tecnologia existe predominantemente em estabelecimentos universitários, organizações tecnológicas e entre a comunidade empresarial, e que as universidades, especificamente, detêm os domínios bem estabelecidos das comunidades eletrônicas. Esse fato facilita a aplicabilidade desse método de recolha para esses públicos, uma vez que estes fazem uso do ambiente virtual em suas rotinas profissionais ou pessoais. Nessa linha, Daley et al. (2003) realizam uma pesquisa via internet com estudantes porque também acreditam que esse público é reconhecido como o mais "alfabetizado em computador" que os outros segmentos da população.

Outras vantagens do método de coleta via web são reveladas por Thach (1995): conveniência do entrevistado, ausência da interferência dos entrevistadores, respostas mais honestas e transparentes do que os métodos tradicionais de recolha, principalmente em questões mais sensíveis. Essa questão das respostas a perguntas "sensíveis" é tema de 
muitas investigações acadêmicas e foi abordada também por Tourangeau e Smith (1996), que creditam ao método de coleta via internet a melhor abordagem para esses temas. A distância social, permitida por esse método, deixa os respondentes mais à vontade para tratar de temas socialmente polêmicos.

Uma vez colocadas as principais vantagens da utilização do método de coleta de dados via web, a revisão teórica apresenta também uma série de desvantagens a saber. "O erro de cobertura é atualmente a maior ameaça da pesquisa via web, ao menos para os grupos além daqueles definidos como usuários da internet" (COUPER, 2000, p. 467). O erro de cobertura, aqui inserido, existe quando não há coincidência entre a população alvo e a população selecionada para representá-la. Fricker et al. (2005) assinalam que as pesquisas por internet oferecem uma cobertura precária dos domicílios da população geral, contrastada, por exemplo, com a cobertura atingida pelo telefone. Baker et al. (2010) complementam apontando que a melhor estimativa de acesso à Internet nos Estados Unidos indica que pelo menos um terço da população adulta não acessa a internet de maneira regular. Isso significa dizer que todos os painéis online ${ }^{4}$ possuem um erro de cobertura inerente e significante.

Pela tabela 1, pode-se observar que, no Brasil, a situação é ainda mais crítica, uma vez que, segundo a PNAD, mais de $80 \%$ da população com mais de 50 anos não acessou a internet, no período de referência, em pesquisa realizada em 2008-2009. Ainda com os resultados desta pesquisa, pode-se observar que o maior acesso, no mesmo período, foi feito pelo grupo etário de 18 a 19 anos e ainda assim, cerca de $30 \%$ dos jovens nessa faixa etária não se conectaram à rede. Considerando-se as macrorregiões brasileiras, o Norte e Nordeste têm, por sua vez, menores índices que a média nacional, incorrer-se-ia em um erro imensurável, representar essas regiões através de uma amostra de usuários de internet.

Tabela 1 - Percentual das pessoas que utilizaram a internet, no período de referência dos últimos três meses, na população de 10 anos ou mais de idade, por Grandes Regiões, segundo os grupos de idade - 2008-2009

\begin{tabular}{|l|c|r|r|r|r|c|}
\hline \multirow{2}{*}{ Grupos de idade } & \multirow{2}{*}{ Brasil } & \multicolumn{5}{|c|}{ Grandes Regiões } \\
\cline { 3 - 7 } & & Norte & Nordeste & Sudeste & Sul & $\begin{array}{c}\text { Centro- } \\
\text { Oeste }\end{array}$ \\
\hline \multicolumn{7}{|c|}{$\mathbf{2 0 0 9}$} \\
\hline Total & $\mathbf{4 1 , 7}$ & $\mathbf{3 4 , 3}$ & $\mathbf{3 0 , 2}$ & $\mathbf{4 8 , 1}$ & $\mathbf{4 5 , 9}$ & $\mathbf{4 7 , 2}$ \\
\hline 10 a 14 anos & 58,8 & 39,9 & 41,8 & 71,1 & 70,2 & 70,3 \\
\hline 15 a 17 anos & 71,1 & 60,0 & 55,1 & 82,1 & 80,6 & 79,5 \\
\hline 18 ou 19 anos & 68,7 & 59,0 & 53,6 & 78,3 & 75,6 & 75,2 \\
\hline 20 a 24 anos & 61,8 & 51,4 & 47,3 & 71,8 & 67,5 & 68,3 \\
\hline 25 a 29 anos & 53,7 & 42,2 & 37,5 & 64,0 & 60,8 & 58,6 \\
\hline 30 a 39 anos & 42,1 & 31,0 & 27,8 & 50,5 & 48,5 & 46,0 \\
\hline 40 a 49 anos & 32,7 & 22,5 & 19,6 & 39,7 & 37,0 & 34,7 \\
\hline 50 anos ou mais & 15,2 & 9,5 & 8,3 & 18,8 & 16,7 & 16,2 \\
\hline
\end{tabular}

Fonte: IBGE - PNAD, 2009.

\footnotetext{
${ }^{4}$ Painéis de respondentes inseridos no contexto web significa estar disponível para acesso imediato a uma página de Internet, em tempo real. Fonte: http:// pt.wikipedia.org/wiki/Online.
} 
Aliada ao problema da cobertura, está a dificuldade de seleção da amostra entre os próprios usuários da internet. Com exceção de alguns públicos específicos (como empregados de companhias e estudantes de instituições de ensino), não existem listas completas de usuários de internet e não há, para essa "população", método de amostragem análogo à discagem randômica (para entrevistas telefônicas), ou à seleção aleatória de domicílios (entrevistas domiciliares). Estáse falando aqui, evidentemente, de amostra probabilística, em que cada membro da população selecionada, tem chance de participação na pesquisa. Fricker et al. (2005) afirmam ainda que a inabilidade em se gerar amostras probabilísticas de usuários de internet torna as pesquisas via web vulneráveis como método único de coleta de dados. "O erro amostral surge pelo fato de que nem todos os membros da população selecionada são abordados; com isso, se o processo amostral for repetido, uma amostra diferenciada de pessoas pode ser obtida" (COUPER, 2000, p.467). Uma solução para esse problema seria selecionar uma amostra probabilística através de outro método (por exemplo, discagem randômica) e tentar persuadir cada membro da amostra a completar o questionário online. Da mesma opinião compartilham Couper e Miller (2008), que ainda sugerem que, se no recrutamento probabilístico forem selecionados potenciais respondentes que não tenham acesso à internet, deve-se providenciar a estes tal acesso para que possam ter a chance de responder à pesquisa.

Baker et al. (2010) reconhecem, então, que os painéis atualmente disponíveis são não probabilísticos e só podem ser uma escolha apropriada quando não se tem a intenção de reproduzir com precisão a população, ou seja, quando não se pretende representá-la com os dados coletados na pesquisa. Couper (2000) revela a delicadeza da situação quando afirma que a inferência estatística só pode ser baseada em desenhos probabilísticos de amostra.

Uma distinção chave deve ser feita entre pesquisas científicas que permitem inferências para a população, e pesquisas de dados coletados onde a ênfase está simplesmente no número de respondentes ao invés de representação. (COUPER, 2000, p. 473).
Outra preocupação quanto ao método de coleta de dados via web refere-se ao índice de respostas. A taxa de retorno de resposta nesse tipo de pesquisa pode ser prejudicada nos diversos estágios da coleta. Primeiro, pela quantidade de $e$-mails (endereços eletrônicos) "não entregues", ou seja, aqueles que não atingiram seus destinatários por erro ou desatualização de cadastro. Segundo, pelo número de contatados que não consegue, por qualquer razão, responder à pesquisa (elegibilidade). E terceiro, pela forma de abordagem, que muitas vezes inibe ou irrita o respondente, desmotivando-o a preenchê-la (FRICKER, 2005).

Outro ponto que compromete o índice de respostas é a heterogeneidade dos recursos tecnológicos disponíveis aos usuários de internet. As múltiplas opções de acesso podem trazer limitações de recursos audiovisuais (tais como, velocidade de conexão, navegadores de internet em diversos estágios etc.) aos seus usuários e, por conseguinte, limitar as possibilidades de acesso a pesquisas.

O tópico índice de respostas é ainda mais crítico quando há viés demográfico ou atitudinal entre os que respondem à pesquisa via web e os que não o fazem por qualquer razão. Kim et al. (2009), em um estudo realizado nesta data, nos Estados Unidos, trazem como resultado que pessoas acima de 45 anos e as de etnia específica tendem a não responder pesquisa por internet. Couper e Rowe (1996) assinalam que respondentes por internet devem, necessariamente, ser alfabetizados e ter experiência com computadores; e Sax et al. (2003) afirmam que, tipicamente, a melhor infraestrutura em telecomunicações e conexões são características de áreas de alto poder aquisitivo.

Em suma, pelas três principais questões apontadas acima (cobertura, amostragem e índice de resposta), pode-se concluir que a "população internet", atingida por pesquisas de mercado via web, é diferente da população geral, abordada por pesquisas presenciais ou telefônicas. Apesar do crescimento contínuo do acesso à rede virtual, imagina-se que essas diferenças persistam por algum q1tempo, dada a pluralidade e dimensão destas. Ora, se em toda investigação social, o pesquisador busca o entendimento geral mais do que expli- 
car eventos individuais (BABBIE, 1999), como devem ser tratados os temas acima expostos? Parece que os desafios para os investigadores via web se põem em: encontrar alternativas criativas para tornar o acesso virtual mais abrangente para a população; misturar métodos de coletas (web + entrevistas telefônicas + entrevistas pessoais), mais conhecidos como abordagem multi-mode; ou em limitar as generalizações dos resultados obtidos à população de usuários da rede, sem ter a pretensão de extrapolá-los para a população geral.

\section{Metodologia da pesquisa}

Para contextualizar o tema no cenário brasileiro, foram realizadas entrevistas exploratórias em profundidade para saber "a percepção de alguns dos principais executivos de institutos de pesquisa de mercado sobre o método de coleta de dados via web".

Segundo Malhotra (2001), a pesquisa exploratória pode ser usada tanto para definir um problema com maior precisão quanto para desenvolver hipóteses sobre esse mesmo problema. Como este artigo tem a intenção de apresentar o estágio no qual se encontra a pesquisa de mercado via web, no mercado brasileiro, essa técnica mostrou-se eficaz.

Além disso, como o referencial teórico trouxe várias vantagens e preocupações quanto a essa técnica de recolha, a proposta, com as entrevistas em profundidade, é entender qual a percepção desses executivos frente a todos esses pontos levantados pelos investigadores acadêmicos. "Em uma entrevista em profundidade, o entrevistador irá explorar cada resposta do entrevistado à exaustão" (TRUJILLO, 2003, p. 44-45). Dessa forma, dado o caráter exploratório da investigação, optou-se pelas entrevistas não estruturadas, ou informais, que contaram com o apoio de um roteiro de discussão para referência dos tópicos a serem abordados. Nesse sentido, o processo de coleta dos dados iniciou-se da mesma forma, tendo o roteiro de discussão como um guia referencial, que se alterou, po- rém, à medida que as discussões prosseguiam e novos caminhos eram desbravados.

A abordagem foi direta, e a análise dos dados, interpretativa (característica do estudo exploratório, não há análise de dados estatísticos, mas sim interpretação das opiniões apresentadas). A análise interpretativa utiliza a exploração dos dados "não intencional" (sem qualquer hipótese inicial) e identifica, inicialmente, alguns fenômenos merecedores de atenção; em seguida, estabelece como esses fenômenos ocorrem de várias maneiras. Segundo Silverman (2009), a análise de uma conversação identifica as sequências da conversa, e busca determinados resultados (por exemplo, uma solicitação de esclarecimento, um reparo, um riso), e olha para trás para traçar uma trajetória seguida para um determinado resultado ser produzido. Isso quer dizer que a interpretação dos dados se dá com algumas observações, antecedidas por um problema, para o qual essas observações poderiam servir como a solução.

As entrevistas com especialistas do setor, pessoas bem informadas sobre o segmento que atuam, podem ajudar a formular o problema. (MALHOTRA, 2001, p. 68).

A finalidade dessas entrevistas é ajudar a definir o problema de pesquisa, e não desenvolver uma solução conclusiva. Isso posto, com o objetivo de situar a pesquisa de mercado via web no Brasil, foram feitas entrevistas em profundidade com seis executivos de seis institutos de pesquisa renomados no Brasil. A tabela 2 fornece um resumo do perfil de cada entrevistado e das empresas nas quais atuam, assim como a data e a duração das entrevistas realizadas. Foram utilizados nomes fictícios para os executivos entrevistados e para as empresas as quais representam, com o objetivo de se manter a anonimidade dos depoimentos, e a confidencialidade das informações fornecidas. Todas as entrevistas foram gravadas e transcritas para posterior análise, e foram todas conduzidas durante os meses de Novembro e Dezembro de 2010 e Janeiro de 2011. 
Tabela 2 - Nome e perfil dos entrevistados

\begin{tabular}{|l|l|l|l|c|c|c|}
\hline $\begin{array}{c}\text { Nome do } \\
\text { entrevistado }\end{array}$ & \multicolumn{1}{|c|}{ Função } & Empresa & $\begin{array}{c}\text { Ramo de } \\
\text { atividade }\end{array}$ & $\begin{array}{c}\text { Atuante } \\
\text { no Brasil } \\
\text { desde }\end{array}$ & $\begin{array}{c}\text { Data da } \\
\text { entrevista }\end{array}$ & Duração \\
\hline Sr. Dutra & $\begin{array}{l}\text { Diretor de } \\
\text { Área }\end{array}$ & Empresa 1 & $\begin{array}{l}\text { Instituto de pes- } \\
\text { quisa de mercado }\end{array}$ & 2001 & $29 / 11 / 2010$ & 1 h14min \\
\hline Sr. Queiroz & Presidente & Empresa 2 & $\begin{array}{l}\text { Instituto de pes- } \\
\text { quisa de mercado }\end{array}$ & 1998 & $06 / 12 / 2010$ & $1 \mathrm{~h} 25 \mathrm{~min}$ \\
\hline Sr. Macedo & Diretor Geral & Empresa 3 & $\begin{array}{l}\text { Instituto de pes- } \\
\text { quisa de mercado }\end{array}$ & 2003 & $02 / 12 / 2010$ & 0h36min \\
\hline Sr. Dias & $\begin{array}{l}\text { Diretor de } \\
\text { Marketing e } \\
\text { Vendas }\end{array}$ & Empresa 4 & $\begin{array}{l}\text { Empresa de tecno- } \\
\text { logia especializada } \\
\text { em coleta de dados }\end{array}$ & 2002 & $29 / 11 / 2010$ & 0 h4 $48 \mathrm{~min}$ \\
\hline Sra. Everest & Sócia-Diretora & Empresa 5 & $\begin{array}{l}\text { Instituto de pes- } \\
\text { quisa de mercado } \\
\text { via internet }\end{array}$ & 2000 & $09 / 12 / 2010$ & $1 \mathrm{~h} 13 \mathrm{~min}$ \\
\hline Sra. Silva & CEO & Empresa 6 & Painéis online & 2008 & $15 / 12 / 2010$ & $0 \mathrm{~h} 46 \mathrm{~min}$ \\
\hline
\end{tabular}

Fonte: Elaborada pelos autores.

Todas as empresas entrevistadas têm como ramo de atividade a condução de pesquisas de mercado, sendo o foco das entrevistas o público em geral ou o público consumidor de determinado produto ou serviço (pessoas físicas ou jurídicas). Conduzem estudos customizados (pontuais e personalizados) e contínuos, e atendem organizações de médio e grande porte, nacionais e multinacionais.

A Empresa 1 é um instituto de pesquisa de mercado tradicional, multinacional, com cerca de 850 funcionários no Brasil; aplica em seus projetos metodologias qualitativas $^{5}$ e quantitativas ${ }^{6}$ e realiza vários tipos de estudos de mercado com o intuito de responder às questões de seus clientes. A área gerenciada pelo Sr. Dutra é responsável por realizar pesquisas de opinião pública e pesquisas sociais, tanto para o mundo corporativo quanto para o setor governamental, neste último caso para subsidiar ou avaliar políticas públicas. A Empresa 1 não possui painel de respondentes próprio, utiliza a base de respondentes fornecida por seus clientes

\footnotetext{
${ }^{5}$ Metodologia de pesquisa não-estruturada, exploratória, baseada em pequenas amostras, que proporciona compreensão do contexto de uma problema.

${ }^{6}$ Metodologia de pesquisa estruturada, baseadas em amostras que permitam quantificar os dados, nos quais se aplicam alguma forma de análise estatística.
}

diretos, ou compra de terceiros para realizar pesquisa via web.

A Empresa 2 também é um instituto de pesquisa de mercado tradicional, nacional, que também se utiliza de metodologias qualitativas e quantitativas na condução dos estudos que realiza; não possui painel de respondentes próprio, e também utiliza a base de respondentes fornecida por seus clientes diretos, ou compra de terceiros, para realizar pesquisa via web.

A Empresa 3 tem o perfil da Empresa 1 , porém em dimensão um pouco menor, uma vez que conta com cerca de 70 funcionários no Brasil. Conduz os mesmos tipos de estudos que a Empresa 1 e 2, para o mesmo perfil de clientes, e aplica metodologias tanto qualitativas quanto quantitativas em seus projetos. A Empresa 3 também não possui painel de respondentes próprio, utiliza a base de respondentes fornecida por seus clientes diretos, ou compra de terceiros, para realizar pesquisa via web.

Já a Empresa 4 é uma empresa nacional de tecnologia especializada em coletas de dados. Possui uma plataforma, que é um software gerenciador de coletas de entrevistas que faz desde a programação do questionário, em qualquer tipo de formato, passando pela gestão dos dados dos respondentes, disparo das entrevistas, até o processamento dos dados coletados. Diferente das outras empresas 
entrevistadas, a Empresa 4 se utiliza apenas da metodologia quantitativa na condução dos estudos que realiza. Não possui painel de respondentes próprio, utiliza a base de respondentes fornecida por seus clientes diretos para realizar pesquisas via web.

A Empresa 5 se autointitula como a pioneira em pesquisa de mercado pela internet. Originada em ambiente virtual, em 2002 começou a se estruturar para realizar coleta de dados via web para pesquisa de mercado. Assim, possui seu próprio painel online de respondentes e, tal qual as Empresas 1, 2 e 3 , utiliza-se das metodologias quantitativa e qualitativa na condução dos estudos que realiza. Possui hoje, em seu quadro de funcionários, 25 colaboradores.

A Empresa 6 também é especialista em pesquisa por internet, possui painel próprio de respondentes via online e oferece apenas a metodologia quantitativa para a realização de estudos de mercado a seus clientes. Possui hoje, em seu quadro de colaboradores, 50 funcionários.

Todas as empresas entrevistadas oferecem a seus clientes o que se chama de full service no mercado de investigação, serviço que abrange desde o desenho do projeto de pesquisa, à coleta de dados, seu processamento ou interpretação, até a apresentação dos resultados finais ao cliente.

Para todos os entrevistados, como já mencionado, foram colocadas questões sobre as vantagens e desvantagens da aplicabilidade da coleta de dados via web, sobre o estágio desse tipo de pesquisa no mercado brasileiro e, finalmente, como lidam com os problemas enfrentados.

\section{Análise dos resultados}

\section{Pontos de convergência}

Os pontos de convergência, entre todas as empresas entrevistadas, referem-se, primeiro, às principais vantagens do método de coleta de dados via web, são elas: baixo custo de aplicação e velocidade de condução. Esses pontos parecem estar em linha com o referencial teórico exposto anteriormente, ou seja, esse método de pesquisa é mais barato e mais rápido que os tradicionais (entrevistas pessoais, por correio e telefônicas). O baixo custo refere-se majoritariamente à ausência dos salários dos entrevistadores, bem como à inexistência dos custos de impressão e de digitação (quando se compara a técnica a entrevistas aplicadas com papel e caneta). Segundo Sr. Dutra, da Empresa 1, "a coleta é simultânea à digitação e à consistência ${ }^{7}$, e a base de dados fica pronta para processamento logo após o término do trabalho de recolha". Isso elimina os gastos e prazos de impressão e digitação dos outros métodos tradicionais e, tão importante quanto, está em linha com as exigências dos clientes atuais, cada vez mais ávidos por informação barata e rápida; barata aqui, não no sentido de baixo valor, ao contrário, informação de alto valor agregado, porém proporcionada por baixos custos de coleta e processamento, através de processos alternativos e modernos. O Sr. Macedo, da Empresa 3, afirma "as grandes vantagens do método online são rapidez e preço."

Segundo Sr. Dias, da Empresa 4, "a primeira vantagem, esmagadora de todas, não é o custo, é o tempo; em uma ocasião, o presidente de uma multinacional de cosméticos precisava compor uma apresentação sobre o mercado brasileiro e solicitou uma pesquisa com 300 consumidoras da categoria; em um dia, os dados foram coletados e processados, e ele pôde usar as informações, no dia seguinte, conforme havia planejado". Isso só é possível porque a metodologia permite também o processamento do dado em tempo real, disponibilizando gráficos e análises conclusivas. Sra. Everest, da Empresa 5, ressalta "como fazer uma pesquisa com mil pessoas, em um dia útil, com resultado em tempo real? Só a internet proporciona isso".

Outro quesito sobre o qual as opiniões se assemelham é quanto à aplicabilidade da técnica de coleta online quando se trata de públicos específicos (segmentos determinados). Todas as empresas entrevistadas conduzem, com certa facilidade, pesquisa de clima organizacional ou pesquisa de satisfação com a base de (potenciais) respondentes do próprio cliente. Nesse caso, organizações interessadas na opinião de seus colaboradores ou clientes, disponibilizam suas bases de dados para a realização de pesquisas. Na opinião dos

\footnotetext{
${ }^{7}$ Identifica os dados que estão fora do padrão, são inconsistentes logicamente ou apresentam valores extremos.
} 
executivos entrevistados, a técnica de coleta de dados para esses públicos é perfeita, pois o universo é conhecido e se pode selecionar tanto uma amostra probabilística, quanto se pode realizar um censo através da base de dados. O Sr. Macedo, da Empresa 3, salienta "quando temos a base dos clientes, podemos realizar estudos online com a mesma facilidade que conduzimos estudos telefônicos". O Sr. Dutra, da Empresa 1, complementa que, além do público interno de empresas e clientes, "alguns públicos como formadores de opinião, jornalistas e tal, também favorecem o uso da técnica, pois, em geral, esse público já tem uma familiaridade muito grande com internet, pela própria função que desempenham em seus ambientes profissionais".

Outro ponto convergente entre as opiniões dos entrevistados refere-se ao fato de que o método de coleta via web veio para ficar, não se trata de um modismo passageiro, mas, ao contrário, quando endereçadas algumas questões ainda pendentes (algumas serão abordadas a seguir), este será o principal método de recolha de dados no meio da investigação social.

Colocados os pontos de concordância de opinião dos entrevistados, cabe também apontar todas as outras vantagens do método mencionadas pelos executivos abordados. Segundo Sr. Queiroz, da Empresa 2, “do ponto de vista de controle de qualidade, é um avanço grande porque é muito mais segura a administração do questionário por um software do que a administração de um questionário por um entrevistador nas condições de trabalho às quais ele está sujeito, de pé, com uma prancheta na mão, com uma pessoa querendo escapar e ele ter que administrar, corretamente, um questionário complexo". ${ }^{8}$ Aqui o Sr. Queiroz refere-se à conveniência do entrevistado em responder à pesquisa no horário e local que bem entender, em vez de ser abordado pelo entrevistador no local e horário que melhor lhe convém. $\mathrm{O}$ entrevistado também acredita que, para temas sensíveis como por exemplo, assuntos financeiros, comportamento sexual, e, às vezes, até problemas de saúde, doença, "o fato de a pessoa estar sozinha permite respostas muito mais verdadeiras, pois não está constrangida

\footnotetext{
$\overline{{ }^{8} \text { Técnica de pesquisa }}$ aplicada em estudos de preço.
}

com a presença de um interlocutor; o método é mais particular, menos invasivo e a pessoa está muito mais propensa a dizer a verdade do que a mentir para ser socialmente correta, em uma interação pessoal, certo?".

O Sr. Dias salienta que uma grande vantagem do método é a administração de pessoas. "Em pesquisa web você não administra pessoas, você administra servidores, e servidores fazem tudo exatamente que você mandar". A Sra. Everest, da Empresa 5, completa "eu fico pensando se eu trabalhasse no mundo offline, eu iria odiar. Ter que cuidar desse público (entrevistadores), ter que checar fraude, ter que lidar com o ser humano de má fé...eu não iria conseguir".

Além disso, Sr. Queiroz também aponta as facilidades tecnológicas pertinentes ao método, "técnicas de pesquisa mais sofisticadas, como trade-off ${ }^{8}$, rankeamento de atributos, são mais facilmente desenvolvidas e aplicadas com tecnologia, recurso que, sabidamente, o papel não oferece", tampouco o telefone.

\section{Pontos de divergência}

Quanto aos pontos de divergência, eles são em menor número quando comparados com os convergentes, porém vitais no posicionamento das empresas entrevistadas; aquelas que ainda consideram esses pontos como problemas a superar, ainda não lançaram mão dos métodos tradicionais de coleta de dados, por ainda não acreditarem que a técnica de coleta via web tenha condições de substituílos parcialmente ou totalmente; já aquelas que, de uma ou de outra maneira, acreditam que essa técnica é o futuro e que esse futuro começa agora, criaram meios de contornar essas dificuldades e já realizam pesquisas via web há anos. De um lado, estão as Empresas 1, 2, 3 e, de outro lado, as Empresas 4, 5 e 6. O primeiro grupo de companhias levanta algumas questões quanto à confiabilidade dos dados coletados via web, apontando como principais preocupações:

- A representatividade da amostra quando o universo a ser investigado é a população geral;

- A disponibilidade de uma base de dados de respondentes que seja completa, atualizada e confiável para estudos com públicos específicos (exceto 
quando a base de dados é do próprio cliente requisitante da pesquisa);

- O perfil específico do respondente online;

- A interação do respondente com o método de coleta online, diretamente atrelada ao índice de "não respostas".

Já o segundo grupo de empresas, por serem especializadas em coleta de dados por internet, não esconde que faceou essas mesmas dúvidas no início de suas operações, mas revelam que, através de tecnologia avançada, melhorias constantes em seus processos e certa dose de criatividade, superaram alguns deles ou ainda estão superando-os, utilizando-se de soluções alternativas. Apenas para efeito didático/analítico, nomear-se-á o primeiro grupo de empresas de "empresas tradicionais" e o segundo grupo de "empresas contemporâneas".

A representatividade da amostra (erro de cobertura) é sem dúvida, a maior preocupação dos executivos dos institutos de pesquisa de mercado representados pelas Empresas 1, 2 e 3. O principal questionamento aponta para o fato de que não são todos os brasileiros que têm acesso à internet, quer seja no próprio domicílio, na escola, no trabalho ou em qualquer outro lugar. Este fato excluiria uma massa significativa de pessoas de qualquer amostra selecionada e comprometeria a generalização dos resultados da pesquisa para a população geral; ou seja, teríamos resposta a perguntas, como em qualquer outro levantamento, porém essas respostas representariam uma população outra que não a população brasileira. Como nenhuma das empresas do grupo nomeado como "tradicional" tem seu próprio painel de respondentes online, todas são levadas a contratar os serviços de outras empresas, tipo as nomeadas como "contemporâneas", para realizar pesquisas via web. O Sr. Dutra, da Empresa 1, enfatiza "Os painéis que existem disponíveis hoje, para representar a população geral, eu ainda não tenho uma avaliação técnica deles o suficiente para confiar". E completa, "qual o critério para a seleção destas pessoas que constam dos painéis? Elas foram recrutadas e estão lá por conta de alguma especificidade que eu não sei qual é... isso tem um viés, e qual é o viés da formação deste público? Eu não sei."
Pelas razões expostas acima, as empresas 1, 2 e 3 atualmente preferem oferecer a seus clientes a pesquisa online apenas quando estes fornecem a base de dados dos potenciais respondentes, ou seja, realizam pesquisa tipo avaliação de ambiente corporativo, de satisfação por produtos comprados/serviços prestados, mas sempre aplicando as entrevistas para a base de respondentes de seus clientes finais. O Sr. Macedo, da Empresa 3, revela que, se um cliente lhe fornece a lista dos compradores de seus produtos ou serviços, ele tem um universo perfeitamente representado nessa lista.

Do grupo de empresas chamado de "contemporâneo", pode-se dizer que há certa controvérsia em relação ao tema erro de cobertura. A Sra. Everest, da Empresa 5, afirma que a questão da representatividade não é mais um problema, "hoje temos $30 \%$ da classe C na web; 35\% do total da população Brasil acima de 10 anos já está na web, e se falarmos de grandes metrópoles, esse número salta para $50 \%$. Então, quando eu falo com classe A, B, C de 16 a 65 anos, não tem mais o que se questionar se o comportamento deste público versus população é diferente". E complementa "Além disso, trabalhamos muito com estudos por cotas, eu acredito nos estudos online por cota, e essas cotas, eu faço com que elas fiquem representativas da população; na verdade, os clientes nem pedem estudos puramente probabilísticos, é sempre para falar com mulheres e homens, de tal idade, de tal classe social, etc.".

Paralelo à questão da representatividade da amostra, caminha o tema da composição das bases de dados de respondentes dos painéis existentes no mercado, quando se tem que fazer uma pesquisa com determinado público. É unânime a preocupação das empresas "tradicionais" quanto à confiabilidade das bases de respondentes disponíveis, principalmente no que se refere à sua atualização. A cada tentativa de se realizar uma pesquisa via web com público específico, há evidências de que essas empresas não estão confortáveis com as bases de dados disponíveis no mercado, que serão utilizadas para os disparos da pesquisa. Além disso, há um complemento para esse fato: como saber se o respondente é a mesma pessoa que consta do cadastro, e não seu filho, amigo ou parente? O Sr. Macedo, representante da Empresa 3, afirma "hoje o 
computador nos lares brasileiros é compartilhado por vários moradores daquele domicílio, não há garantias de que a pessoa que eu pretendo atingir na minha pesquisa será realmente quem vai respondê-la, e não um irmão, um amigo ou um parente". Esse tópico é completamente combatido pelas empresas de painéis online que aqui fazem parte do grupo das "contemporâneas". Segundo Sra. Everest, da Empresa 5, esse problema ficou no passado, uma vez que existem recursos certificadores da identificação do panelista e vários processos já implementados de atualização dessas bases de dados.

O fato de esse método de coleta estar vinculado a meios avançados de informação, permite ainda que alguns recursos tecnológicos sejam utilizados para aprimorar ainda mais esses controles. Sr. Everest menciona "há um controle rigoroso dos IPs que respondem às pesquisas, sempre atrelados aos cadastros dos respondentes". E a Sra. Silva aprimora "utilizamos até geo validação para verificar se existem pessoas com o mesmo nome ou sobrenome morando na mesma cidade, com a mesma data de nascimento, por exemplo". Todos esses procedimentos parecem assegurar às empresas de painéis que a pessoa que está do outro lado do monitor, respondendo à pesquisa, é realmente a que se pretende atingir para aquela investigação.

Um terceiro tópico relevante parece ser o perfil do respondente online. Possui ele características diferentes do respondente não conectado? São públicos que têm os mesmos hábitos e comportamentos atitudinais? Essas são perguntas apontadas pelas empresas aqui nomeadas como "tradicionais". Sr. Dutra afirma "por exemplo, existem painéis que são coletados a partir de sites de relacionamentos, e isso tem um viés, como praticamente toda a pesquisa tem. O problema aqui é que eu não sei qual é o viés de estar entrevistando um painel que é formado desta forma. Quando a coleta é face a face eu tenho uma abrangência maior, consigo selecionar áreas, consigo compor a classe social do indivíduo e ver isso dentro da população, então... quando eu tenho um método online desse tipo, eu não sei o viés da formação daquele público. Vários desses painéis têm classe $C, D$, só que essas pessoas foram recrutadas e estão lá por conta de alguma especificidade que eu não sei qual é. Eu não tenho como controlar isso".
Finalmente, o último ponto apontado pelos entrevistados é quanto à interação do respondente com o método de coleta online, e os questionamentos giram em torno do quanto o autopreenchimento assegura uma interpretação homogênea das questões por todos os entrevistados e o quanto ele é apropriado para extrair a informação mais adequada do respondente, sobre qualquer tema. $\mathrm{O}$ primeiro questionamento passa por dois efeitos negativos: interpretações diferentes de determinada pergunta podem ocasionar resultados não coerentes entre os entrevistados, e interpretações dúbias podem causar confusão e colaborar para o índice de "não respostas"; o segundo, e talvez mais conflitante, é a questionável capacidade do método de coletar informação precisa, clara e coerente do entrevistado, pelo fato de não haver entrevistador intermediando a conversa, esclarecendo possíveis dúvidas. OSr. Dutra, da Empresa 1, observa "no contato presencial ou telefônico, o entrevistador tenta evitar que outras pessoas afetem a concentração do respondente, tenta isolar o entrevistado para que ele fique mais à vontade. Se estiver na casa do indivíduo, procura eliminar a influência da presença de outras pessoas da família. Na técnica online, não temos esse controle. Não sabemos se a pessoa está sozinha ou com alguém do lado, olhando o questionário, opinando e tal". E completa: "na técnica presencial, ou mesmo na telefônica, há um entrevistador treinado intermediando, ele está preparado para ouvir, para entender determinadas questões e perceber se uma questão foi mal compreendida, enfim, há ainda um controle sobre a interação nas duas técnicas tradicionais. No online isso ainda não é possível, não há forma alguma de acompanhar, nem controlar como está sendo realizada aquela interação".

\section{Conclusões e recomendações}

Os institutos de pesquisa brasileiros faceiam as mesmas questões metodológicas da coleta de dados via web apontadas pelos artigos acadêmicos publicados que abordam o tema. Nas entrevistas exploratórias realizadas com os principais executivos, representantes de alguns desses institutos, pôde-se perceber que o número de vantagens na utilização desse método de coleta supera o número de 
desvantagens, mas estas últimas ainda são consideravelmente significantes para conduzir todos à adesão da técnica.

As vantagens da aplicabilidade da pesquisa via web são evidentes para todos os entrevistados: baixo custo, maior velocidade de condução, adequação para determinados públicos, possibilidade de o entrevistado interagir à sua conveniência, adequação para abordar temas sensíveis, alto poder de distribuição e oferta intrínseca de recursos tecnológicos perfeitamente aplicáveis à técnica, vantagens essas apontadas quando compara-se este método de recolha com os métodos tradicionais, como por exemplo, entrevistas presenciais e telefônicas. Por essa lista de pontos favoráveis, era de se esperar que a pesquisa via web no Brasil estivesse sendo utilizada em larga escala para a coleta de dados de mercado, mas, de acordo com as entrevistas realizadas, sua utilização ainda é restrita pelo fato de existirem alguns temas ainda polêmicos que oferecem resistência à sua total aplicabilidade, são eles: inadequação para representar a população geral, falta de confiabilidade nas bases de dados de respondentes disponíveis, perfil diferenciado do internauta e sua interação, ainda desconhecida, com o método.

As entrevistas exploratórias realizadas evidenciaram que as empresas de painéis online, até por sua constituição original, estão mais inseridas no contexto da técnica de coleta via web quando comparadas com os institutos tradicionais de pesquisa de mercado e, por essa razão, trabalham continuamente para superar as principais deficiências apontadas: procuram realizar estudos que possuem cotas de perfis de entrevistados (predeterminação do número de mulheres e homens, de classe social, de idade etc.), ou utilizam métodos combinados de coletas (online e recrutamento face a face, por exemplo) para superar a ausência de determinados perfis no painel. Com estas ações, estão conscientes de que conseguem realizar um número suficiente de entrevistas dos perfis de respondentes desejados, o que possibilita análise dos resultados, mas não têm a pretensão de que esses resultados sejam representantes da população geral. Quanto à confiabilidade em suas bases de dados, as empresas de painéis online possuem uma certa tranquilidade quanto ao tema, pois desenvolveram processos de atualização contínua dessas bases, o que assegura sua fidedignidade.

Os tópicos que ainda representam uma preocupação, mais evidente para os institutos de pesquisa tradicionais, e que não são descartados pelas empresas de painéis online, referem-se ao perfil do internauta e sua interação com o método eletrônico de coleta de dados. As principais questões giram em torno do fato de que ainda não se tem a grande maioria da população brasileira conectada à internet por diversas razões, e essas mesmas razões fazem com que o perfil dos conectados seja distinto daqueles que não têm acesso à rede, diferença essa que pode estar refletida em seu padrão comportamental e atitudinal, e por assim dizer, pode vir a influenciar as respostas dadas às perguntas das pesquisas endereçadas a eles.

Sugere-se para futuras investigações entender como as empresas de painéis online realizam as pesquisas via web passo a passo, evidenciando, caso existam, diferenças dos processos de pesquisa dos métodos tradicionais (presencial e telefônico), cobrindo temas tais como abordagem do entrevistado, instrumento de coleta, recursos utilizados para não entrar na lista negra dos respondentes como emissor de mensagens indesejadas, etc. Além disso, sugere-se a realização de uma pesquisa utilizando-se um método de coleta tradicional e o método de coleta online para comparação de resultados recolhidos.

\section{Referências}

BABBIE, Earl. Métodos de pesquisa de Survey. Tradução de de Guilherme Cezarino. Belo Horizonte: Editora UFMG, 1999.

BAKER, R.; BLUMBERG, S. J.; BRICK, J. M.; COUPER, M. P.; COURTRIGHT, M.; DENNIS, J. M.; DILLMAN, D.; FRANKEL, M. R.; GARLAND, P.; GROVES, R. M.; KENNEDY, C.; KROSNICK, J.; LAVRAKAS, P. J. Research Synthesis: AAPOR Report on Online Panels. Public Opinion Quarterly. v. 74, n. 4, p. 711-781, dez./ fev. 2010.

BETHLEHEM, J. Selection Bias in Web Surveys. International Statistical Review. v. 78, n. 2, p. 161-188, 2010.

COUPER, M. P. Web Surveys a review of issues and approaches. Public Opinion Quarterly. v. 64, p. 464-494, 2000.

COUPER, M. P.; MILLER, P. V. Web survey Methods: Introduction. Public Opinion Quarterly. v. 72, n. 5, p. 831-835, 2008. 
COUPER, M. P.; ROWE, B. Evaluation of a computer-assisted self-interview component in a computer-assisted personal interview survey. Public Opinion Quarterly, v. 60, n. 1, p. 89-105, 1996.

DALEY, E. M.; McDERMOTT R. J.; BROWN K. R. M.; KITTLESON M. J. Conducting Web-based Survey Research: A Lesson in Internet Designs. Am J Health Behav., v. 27, n. 2, p. 116-124, 2003.

DILLMAN, Don A. Mail and Internet Surveys: The Tailored Design Method. 2. ed. Nova York: John Wiley and Sons, 1999.

FLEMING C. M.; BOWDEN M. Web-based surveys as an alternative to traditional mail methods. Journal of Environmental Management. v. 90, p. 284-292, 2009.

FRICKER, S.; GALESIC, M.; TOURANGEAU, R.; YAN, T. An Experimental Comparison of Web and Telephone Surveys. Public Opinion Quarterly. v. 69, n. 3, p. 370-392, set./nov. 2005.

GUNTER, B; NICHOLAS, D.; HUNTINGTON, P.; WILLIAMS, P. Online versus Offline Research: implications for evaluating digital media. Aslib Proceedings, v. 54, n. 4, p. 229-239, jan. 2002.

KIESLER, Sara. Culture of the Internet. Mahwah, NJ: Lawrence Erlbaum Associates Publishers, 1997.

KIM, J.; KANG, J.; KIM, S.; SMITH, T. W.; SON, J.; BERKTOLD, J. Comparison between Self-administered Questionnaire and Computer-assisted Self-interview for Supplemental Survey Nonresponse. Field Methods, 22:57, 2009.
MALHOTRA, Naresh K. Pesquisa de marketing: uma orientação aplicada. Tradução de Nivaldo Montingelli Jr. e Alfredo Neves de Farias. 3. ed. Porto Alegre: Bookman, 2001.

McDONALD, H.; ADAM, S. A comparison of online and postal data collection methods in marketing research. Emerald Marketing Intelligence \& Planning, v. 21, n. 2, p. 85-95, 2003.

SAX, L. J.; GILMARTIN, S. K.; BRYANT A. N. Assessing Response Rates and NonResponse Bias in Web and Paper Surveys. Research in Higher Education, v. 44, n. 4, ago. 2003.

SILVERMAN, D. Interpretação de dados qualitativos: métodos para análise de entrevistas, textos e interações. Tradução de Magda França Lopes. 3. ed. Porto Alegre: Artmed, 2009.

SPROULL, Lee; KIESLER, Sara. Connections: New Ways of Working in the Networked Organization. CambridgeMA: The MIT Press, 1991.

THACH, L. Using Electronic Mail to Conduct Survey Research. Educational Technology, p. 27-31, mar./abr. 1995.

TOURANGEAU, R.; SMITH, T.W. Asking Sensitive Questions: The Impact of Data Collection Mode, Question Format, and Question Context. Public Opinion Quarterly, v. 60, p. 275-304, 1996.

TRUJILLO, Victor. Pesquisa de mercado qualitativa e quantitativa. 2. ed. São Paulo: Scortecci, 2003. 